\title{
Hormone Receptors and Her-2/neu Overexpression in Breast Carcinomas in Patients of West African Origin Seen at Lagos State University Teaching Hospital, Nigeria
}

\author{
Daniel Ayodele Sanni ${ }^{1}$ Abiodun Olaniyi Popoola ${ }^{2}$ Nasiru Akanmu Ibrahim ${ }^{3}$ Foluso Oyeropo Omodele ${ }^{3}$ \\ Festus Edobor Emiogun ${ }^{1}$ Mobolaji Adewale Oludara ${ }^{3}$ John Oladapo Obafunwa ${ }^{1}$
}

${ }^{1}$ Department of Pathology and Forensic Medicine, Lagos State University Teaching Hospital, Ikeja, Lagos, Nigeria

2Department of Radiology, Oncology Unit, Lagos State University Teaching Hospital, Ikeja, Lagos, Nigeria

${ }^{3}$ Department of Surgery, General Surgery Unit, Lagos State University Teaching Hospital, Ikeja, Lagos, Nigeria

\author{
Address for correspondence Daniel Ayodele Sanni, MBBS, FMCPath, \\ Department of Pathology and Forensic Medicine, Lagos State \\ University Teaching Hospital, 1-5 Oba Akinjobi Way, Ikeja, Lagos \\ 100271, Nigeria (e-mail: ayodele_sanni@ymail.com; \\ daniel.sanni@lasucom.edu.ng).
}

\begin{abstract}
Keywords

- breast cancer

- one-stop breast cancer clinic

- automated immunohistochemistry

Breast carcinoma is a disease of utmost concern to the individual, family, and society at large. The current trend in the management of breast carcinoma also involves hormonal therapy. Consequently, the hormone expression of the tumor in the individual involved must be known if he or she is to benefit from such therapy. This is a prospective study of estrogen and progesterone receptors as well as Her-2/neu overexpression in all breast carcinomas seen at the Lagos State University Teaching Hospital, Ikeja, Nigeria, between April, 1, 2016, and September, 30, 2018. The total number of cases analyzed during the period under study was 107, comprising 105 women and 2 men with an age range of 26 to 88 years and a mean age of $52 \pm 13$ years. The tumors fell into histologic grade II (71.0\%) and grade III (29.0\%). They expressed ER, PR, and Her-2/ neu positivity in $42.1 \%, 33.6 \%$, and $30.8 \%$ of the cases, respectively. Triple-negative breast cancer was $35.5 \%$. Male breast cancers presented as invasive ductal carcinoma and exhibit similar staining pattern as the female breast cancer. In conclusion, this study shows that breast carcinomas occurred predominantly in females of younger age and present with tumors, most of which were of high grade and exhibit triple negativity. This observation is relevant to any therapeutic decisions and management of these patients. Improvement in breast carcinoma screening programs so that the disease can be detected early is also advocated.
\end{abstract}

DOI https://doi.org/ $10.1055 / \mathrm{s}-0041-1729347$ ISSN 2454-6798
(O2021. Spring Hope Cancer Foundation \& Young Oncologist Group of Asia.

This is an open access article published by Thieme under the terms of the Creative Commons Attribution-NonDerivative-NonCommercial-License, permitting copying and reproduction so long as the original work is given appropriate credit. Contents may not be used for commercial purposes, or adapted, remixed, transformed or built upon. (https://creativecommons.org/licenses/by-nc-nd/4.0/).

Thieme Medical and Scientific Publishers Pvt. Ltd. A-12, 2nd Floor, Sector 2, Noida-201301 UP, India 


\section{Introduction}

Breast cancer is the most common malignancy worldwide. ${ }^{1-4}$ It is also a significant cause of mortality with an annual prevalence of 1,000,000 cases worldwide..$^{1-5}$ Mortality from breast cancer is high in sub-Saharan Africa because of the late presentation, and the tumors tend to be very aggressive.,2,46 Breast cancer is heterogeneous and characterized by genetic abnormalities in which TP53 and GATA3 mutations are commonly found in breast cancers in the Nigerian population. ${ }^{7}$

There was a rise in the incidence of breast cancers in Nigeria, from 13.8 to 15.3 per 100,000 in 1992 to 33.6 per 100,000 in year 2000 , as shown by studies done in Ibadan. ${ }^{6}$ The incidence of breast cancers increases with age until menopause, following which a decrease is observed. ${ }^{1}$ The average Nigerian woman with breast cancer presents at a mean age of 47 years, which is earlier than the average of 60 years observed in her Western counterparts. ${ }^{2}$ In other words, most cases of breast cancer in African women are mainly premenopausal while they are postmenopausal in the Western countries. ${ }^{8}$

The incidence of breast cancer in men is $1 \%$ of breast cancers in Western countries but $~ 15 \%$ in sub-Saharan Africa. ${ }^{9,10}$

Invasive ductal carcinoma has been variously reported as the commonest form of breast cancer. ${ }^{11-14}$ Estrogen and progesterone, among other hormones, are important in the development, growth, and function of the female breast. The breast also expresses some growth factors which include human epidermal receptors (Her-2/neu). Breast tumors may or may not express estrogen, progesterone, and Her-2/neu receptors. Estrogen receptors (ERs) are ligand-activated transcription factors which are classified as nuclear hormone receptor superfamily. Progesterone receptors (PRs) have two important and predominant isoforms, these are PR-A and PR-B. ${ }^{15}$ The human epidermal receptor protein-2 (Her-2/neu; C-erb B-2) oncogene protein is a transmembrane glycoprotein in the epidermal growth factor receptor family and is expressed at low levels in breast duct epithelium. ${ }^{16}$ There is amplification of the Her-2/neu gene and associated protein overexpression in $\sim 10$ to $20 \%$ of primary breast cancers. ${ }^{16}$ Expression of these receptors has a positive correlation with prognosis and response to hormonal therapy.

Immunohistochemistry (IHC) is important in the detection of these receptors in breast cancers.

Automated IHC reduces down time on running a protocol, gives better reproducible results, and reduces the wastages of antibodies when compared with manual IHC. ${ }^{17}$ The present study was undertaken to ascertain the true expression of ER, PR, and Her-2/neu by breast cancers in a "one-stop breast cancer clinic," where preanalytical factors are well controlled to ensure best results. The outcome of this study will further impact the way patients with breast cancers are managed.

\section{Methods}

\section{Study Area}

This is a prospective study that was performed in the department of Pathology and Forensic Medicine, Lagos State
University Teaching Hospital (LASUTH), Ikeja, Lagos State, Nigeria, between April, 1, 2016, and September, 30, 2018. Lagos State is the commercial nerve center and the most populous state in Nigeria with approximately 20 million inhabitants. The state attracts people from all parts of the country, as well as foreign nationals, thus adding to the large population and diversity. LASUTH has 740 beds, and it is a large referral center for all general and private hospitals within and outside the state. The department of Pathology and Forensic Medicine receives histopathological samples from the "one-stop breast cancer clinic" within the department, which adopts a multidisciplinary approach to the management of breast cancers. The multidisciplinary team is composed of surgeons, pathologists, radiotherapists, oncologists, and oncology nursing assistants. The preanalytical factors are well controlled to ensure the best outcome.

The authors set out to find out the proportion of expression of ER, PR, and Her-2/neu overexpression in breast carcinomas in LASUTH. Other objectives include the determination of any correlation between the age of patients, the histologic grade of the breast carcinoma, and ER and PR expression.

\section{Patients}

All patients who were newly diagnosed with breast cancer and had core needle biopsies done in our "one-stop breast cancer clinic" were included in the study. Cases from peripheral medical centers and private and general hospitals within and outside the state were excluded from the study. Breast samples from patients on chemotherapy and/or radiotherapy were also exempted from the study.

Patients were recruited through the clinic; they comprised those who had palpable breast lesions.

\section{IHC and Scoring}

Two passes or more of core needle biopsy of the breast were taken and the samples were immediately fixed in 10\% neutral buffered formalin. The grossing of these tissues and subsequent processing were done within 24 hours and not less than 8 hours. The formalin-fixed paraffin-embedded blocks were sectioned at $4 \mu$ and placed on a commercially prepared charged slide. Control blocks of positive breast cancer cases were also cut and placed on the same slide. The slides were loaded onto the Ventana Benchmark GX machine (SN 815224; REF 750-850; Ventana Medical Systems incorporation, Tucson, Arizona, USA) used for auto immunostaining in our facility. The immunostaining protocol used for the runs is as follows, and the machine has been programmed accordingly:

1. The sections were deparaffinized.

2. Antigen retrieval was done using the slide heater in Ventana Benchmark.

3. The incubation time was for 60 minutes at $100^{\circ} \mathrm{C}$.

4. The primary antibody used for ER was anti-ER(SP1 supplied by Roche) at an incubation time of 16 minutes at $42^{\circ} \mathrm{C}$. Counterstaining with haematoxylin was at 4 minutes and post counterstaining with bluing agent at 4 minutes.

5. The primary antibody used for PR was anti-PR(1E2 supplied by Roche) at an incubation time of 26 minutes at $42^{\circ} \mathrm{C}$. 
Counterstaining was with haematoxylin for 12 minutes and post counterstaining with bluing agent at 26 minutes.

6. The primary antibody used was Her-2/neu, 4B5 (supplied by Roche) at an incubation time of 32 minutes at $42^{\circ} \mathrm{C}$. Counterstaining was with haematoxylin for 4 minutes and post counterstaining with bluing agent for 4 minutes.

7. Full automated staining was done within the Benchmark.

8. Consumables were supplied by Roche and bulk fluid usage include the following: cell conditioner 1 , lot number (131795-01; 231342-01), easy prep (132 322-01; 245 650-01), liquid cover slipping (128 746-01, 128746-01, 245 657-01), and reaction buffer (138 025-01, 193 461-01).

9. The slides were retrieved from the machine and washed gently in soapy water after a run of 2 hours and 30 minutes. The slides were then dried and cover-slipped with DPX mountant.

The slides were subsequently reviewed by pathologists who are experienced in IHC techniques.

The scoring was according to the 2013/2018 updated American Society of Clinical Oncology/College of American Pathologists recommendation for ER, PR, and Her-2/neu scoring. ${ }^{18,19}$ The staining pattern for ER is positive if there is intense nuclear staining $\geq 1 \%$ of tumor cells. The staining pattern for PR is positive if there is intense nuclear staining $\geq 1 \%$ of tumor cells. The staining pattern score for Her-2 staining assessment are as follows:

- No membrane staining is observed $=0$ negative.

- Faint, incomplete membrane staining barely perceptible within $>10 \%$ of tumor cells $=1+$ negative.

- Circumferential membrane staining that is incomplete and/or weak/moderate and within $>10 \%$ of tumor cells or complete and circumferential membrane staining that is intense and within \&\#x2264;10\% of tumor cells $=2+$ equivocal.

- Circumferential membrane staining that is complete, intense, and within $>10 \%$ of tumor cells $=3+$ positive.

\section{Statistical Analysis}

Data were collected in an Excel database from Windows 10 (Microsoft Corporation, Redmond, Washington, United States). Statistical significance was set at $p<0.05$. Data were analyzed using chi-square test. Statistical analysis was performed using the Statistical Package for Social Science (SPSS, IBM SPSS Statistics for Windows, version 25.0, IBM Corp., Armonk, NY) version 25 for windows and Microsoft Excel 2013.

\section{Results}

There were 107 specimens from 3 (2.8\%) males and 104 (97.2\%) females with age range of 26 to 88 years. The mean age was $52 \pm 13$ years. As depicted in - Fig. 1, majority of the patients (56.0\%) were within the age group of 40 to 59 years, $28.0 \%$ were aged60 years or older, while $1.9 \%$ were younger than 30 years. There were 61 (57.0\%) left and $46(43.0 \%)$ right-sided breast cancer cases, out of which 31 (29.0\%) were histologic grade II and 76 (71.0\%) were grade III.
ER, PR, and Her-2/neu positivity are shown in - Table 1. More than half of the IHC markers were negative and 35.5\% were triple negative (-Fig. 2); $57.9 \%$ was ER negative and $42.1 \%$ was ER positive.

Likewise, PR and Her-2/neu negatives were 66.4\% and $65.4 \%$ while positives were $42.1 \%$ and $33.6 \%$ respectively. Her-2/neu equivocal was $3.8 \%$. Her-2/neu distribution, negative ( 0 and 1 ), equivocal, and Her-2/neu $3+$, is shown in -Fig. 3. The staining pattern of the hormone receptors is shown in - Fig. 4.

There are 31 (40.8\%) grade III ER-positive and 45 (59.2\%) ER-negative cases while grade II showed 14 (45.2\%) ER-positive and 17 (54.8\%) ER-negative cases, as shown in

- Table 2.

- Table 3 shows 35.5\% grade III PR-positive and 64.5\% PR-negative cases while grade II had 29.0\% PR-positive and $71.0 \%$ PR-negative cases. Among grade III breast cancer cases seen in this study, $67.1 \%$ were Her-2/neu negative and $28.9 \%$ positive, while $3.9 \%$ were equivocal. Grade

Table 1 Immunohistochemistry markers $(n=107)$

\begin{tabular}{|l|l|l|l|l|}
\hline Marker & Positive & Negative & Equivocal & p-Value \\
\hline ER & $45(42.1 \%)$ & $62(57.9 \%)$ & - & \multirow{2}{*}{0.218} \\
\cline { 1 - 2 } & $36(33.6 \%)$ & $71(66.4 \%)$ & - & \multirow{2}{*}{} \\
\cline { 1 - 3 } Her-2/neu & $33(30.8 \%)$ & $70(65.4 \%)$ & $4(3.8 \%)$ & \\
\cline { 1 - 3 }
\end{tabular}

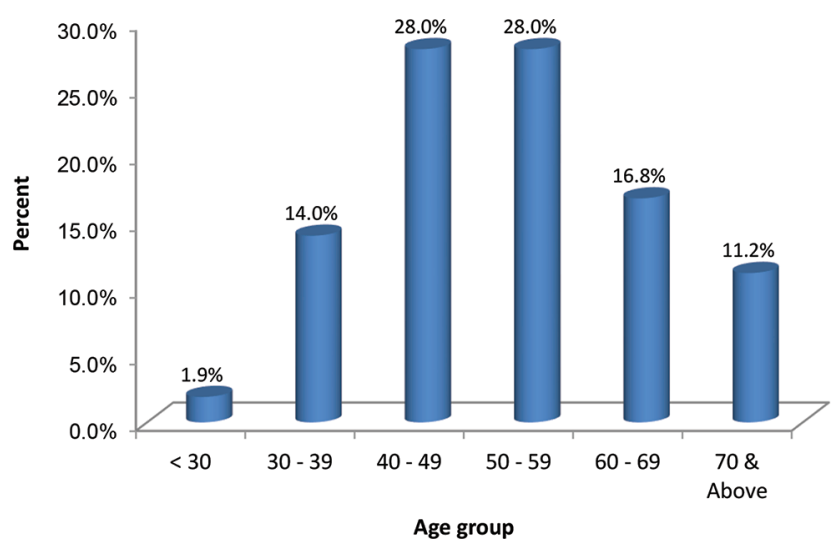

Fig. 1 Age category of patients.

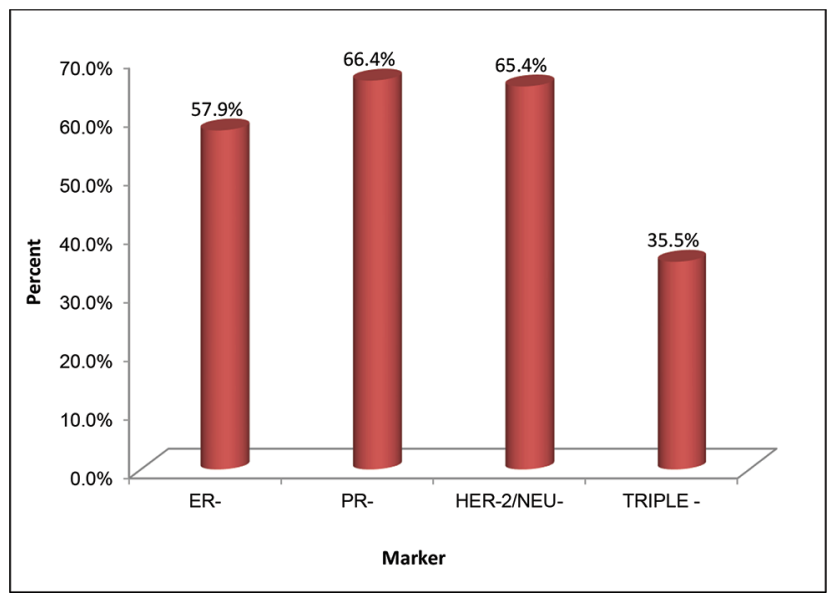

Fig. 2 IHC-negative only. IHC, immunohistochemistry. 


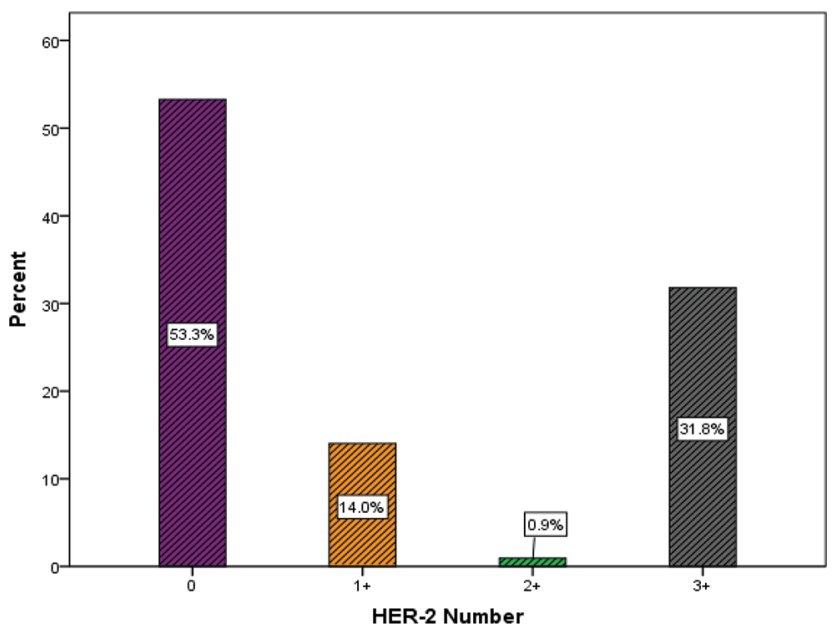

Fig. 3 Her-2/neu positivity.

Table 2 Estrogen receptor versus histological grade $(p=0.678)$

\begin{tabular}{|l|l|l|l|}
\hline Marker & \multicolumn{2}{|l|}{ Histological grade (\%) } & \\
\hline & II & III & Total \\
\hline Positive & $14(45.2 \%)$ & $31(40.8 \%)$ & $45(42.1 \%)$ \\
\hline Negative & $17(54.8 \%)$ & $45(59.2 \%)$ & $62(57.9 \%)$ \\
\hline Total & $31(100.0 \%)$ & $76(100.0 \%)$ & $107(100.0 \%)$ \\
\hline
\end{tabular}

II had 61.3\% Her-2/neu-negative, 35.5\% positive, and 3.2\% equivocal cases. However, there was no statistically significant difference between Her-2/neu status of histologic grades II and III cancer (Table 4). The three male breast cancers were all ER positive, PR positive, and Her-2/neu negative. Two were of histologic grade III and one was grade II.

\section{Discussion}

The study shows that the mean age at diagnosis is 52 \pm 13 years. This agrees with studies done among black Africans. ${ }^{2}$ However, it contrasts with the age of 60 years at diagnosis reported for Caucasians. ${ }^{2}$ Population demographics and genetic variation may account for the differences. ${ }^{20}$ Furthermore, breast carcinomas are common in premenopausal Africans compared with Caucasians with a majority of breast carcinomas occurring in postmenopausal women. ${ }^{8}$ The average age at menopause in Africans varies between 46 and 49 years as against an average of 50 years worldwide. ${ }^{21-23}$ Higher incidence of premenopausal breast cancer in Africans is related to population demographics. The life expectancy in Africans is very much lower than Caucasians..$^{20}$ Environmental factors may be related. ${ }^{20}$

All our patients presented with tumor in grade II (71.0\%) and grade III (29.0\%). This agrees with the results found in other black African countries. ${ }^{24}$ Late presentations and aggressive tumor biology are reasons for the occurrence of breast tumors of higher grade in African women. ${ }^{24}$

The tumors in this study are predominantly triple hormone receptor negative. Similar observations were made by several studies done among Africans. ${ }^{25-28}$ Estrogen receptor reactivity was $42.1 \%$ which was comparatively higher than two other
Table 3 Progesterone receptor versus histological grade $(p=0.519)$

\begin{tabular}{|l|l|l|l|}
\hline Marker & \multicolumn{2}{|l|}{ Histological grade (\%) } & \\
\hline & II & III & Total \\
\hline Positive & $9(29.0 \%)$ & $27(35.5 \%)$ & $36(33.6 \%)$ \\
\hline Negative & $22(71.0 \%)$ & $49(64.5 \%)$ & $71(66.4 \%)$ \\
\hline Total & $31(100.0 \%)$ & $76(100.0 \%)$ & $107(100.0 \%)$ \\
\hline
\end{tabular}

Table 4 Her-2/neu versus histological grade $(p=0.790)$

\begin{tabular}{|l|l|l|l|}
\hline Marker & \multicolumn{2}{|l|}{ Histological grade (\%) } & \\
\hline & II & III & Total \\
\hline Positive & $11(35.5 \%)$ & $22(28.9 \%)$ & $33(30.8 \%)$ \\
\hline Negative & $19(61.3 \%)$ & $51(67.1 \%)$ & $70(65.4 \%)$ \\
\hline Equivocal & $1(3.2 \%)$ & $3(3.9 \%)$ & $4(3.8 \%)$ \\
\hline Total & $31(100.0 \%)$ & $76(100.0 \%)$ & $107(100.0 \%)$ \\
\hline
\end{tabular}

studies done in Nigeria, which both reported 25\%.17,26 The present authors believe that variations in protocols, preanalytical variables, and the use of an automated equipment in our facility most probably account for the low values reported from other parts of the country. The one-stop diagnostic breast clinic at the authors' facility not only minimizes preanalytic variables, but also benefits the patient. It does offer a quick diagnosis and initiation of treatment. Consequently, the patient is not lost in the course of delays in getting the samples taken, diagnosis made, and treatment initiated.

This study has shown that some antiestrogens and antihormonal drugs targeting breast carcinomas may be less effective in many Africans.

Nonreactivity was found to have increased with high-grade tumors but there is no correlation of ER/PR hormonal status with grading. This observation contrasts that of Suvarchala and Nageswararao. ${ }^{29}$

Coexpression of hormones is said to be important in the pattern of metastases of breast tumors and responsiveness to treatment. Negativity for ER and PR (ER-PR-) was found to dominate all age groups and it increases with the grade of the tumors. Furthermore, ER+PR+, ER+PR-, and ER-PR+ have inverse relationship with the grade of tumor. This is in keeping with observations made by Suvarchala and Nageswararao, as well as Fatima, Faridi, and Gill in India and Pakistan, respectively. ${ }^{29,30}$

Her-2/neu positivity does not correlate with higher-grade tumors in this study. This observation contrasts that of Azizun-Nisa et al. ${ }^{31}$

It is noteworthy that male breast cancers seen in this study display invasive ductal carcinoma and behave like the female breast cancer. Similar observations were made by authors in Turkey and the United States. ${ }^{32,33}$

\section{Conclusion}

This study highlights the fact that breast carcinomas in Africans seem to occur in younger age and they present with 

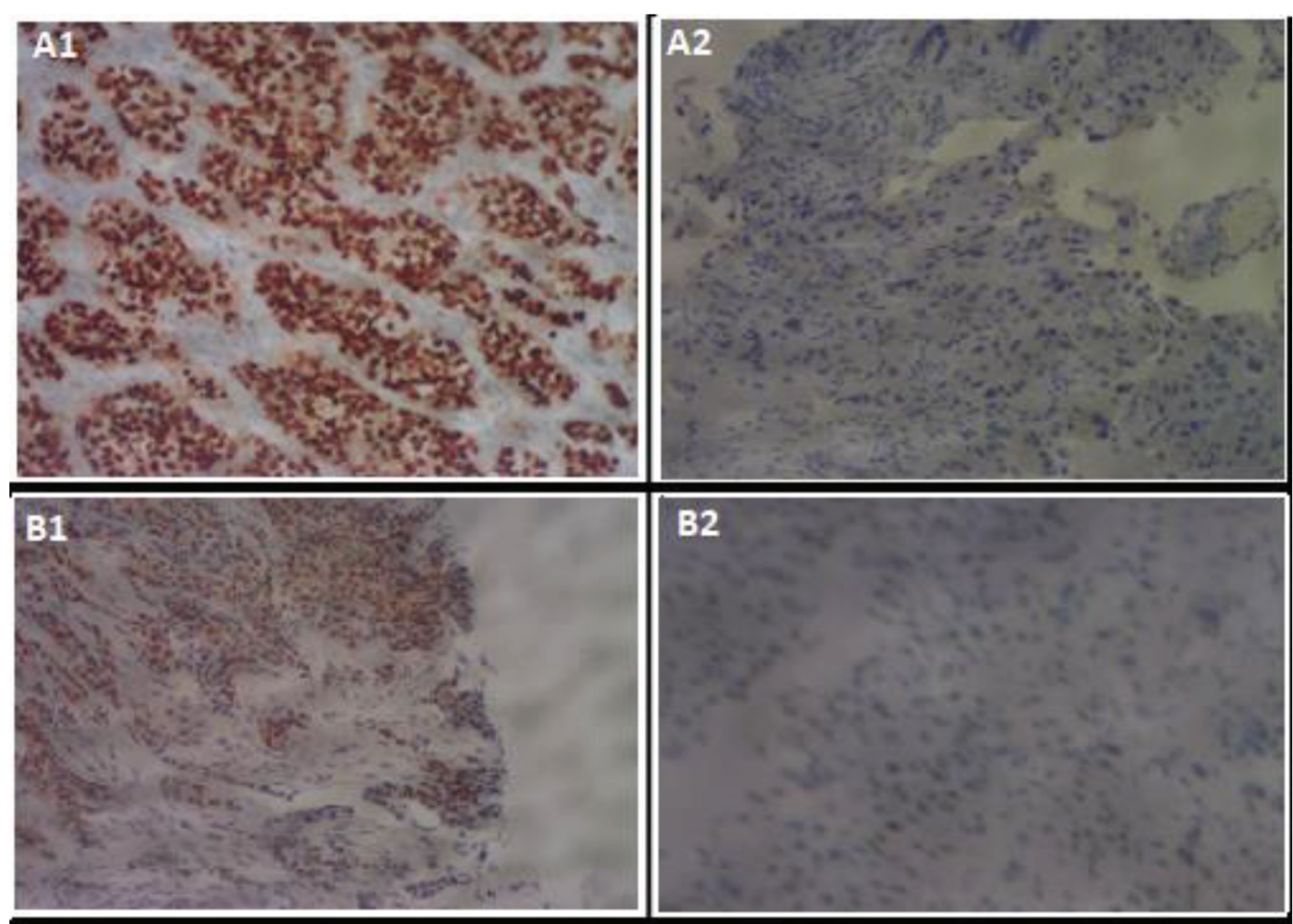

B2
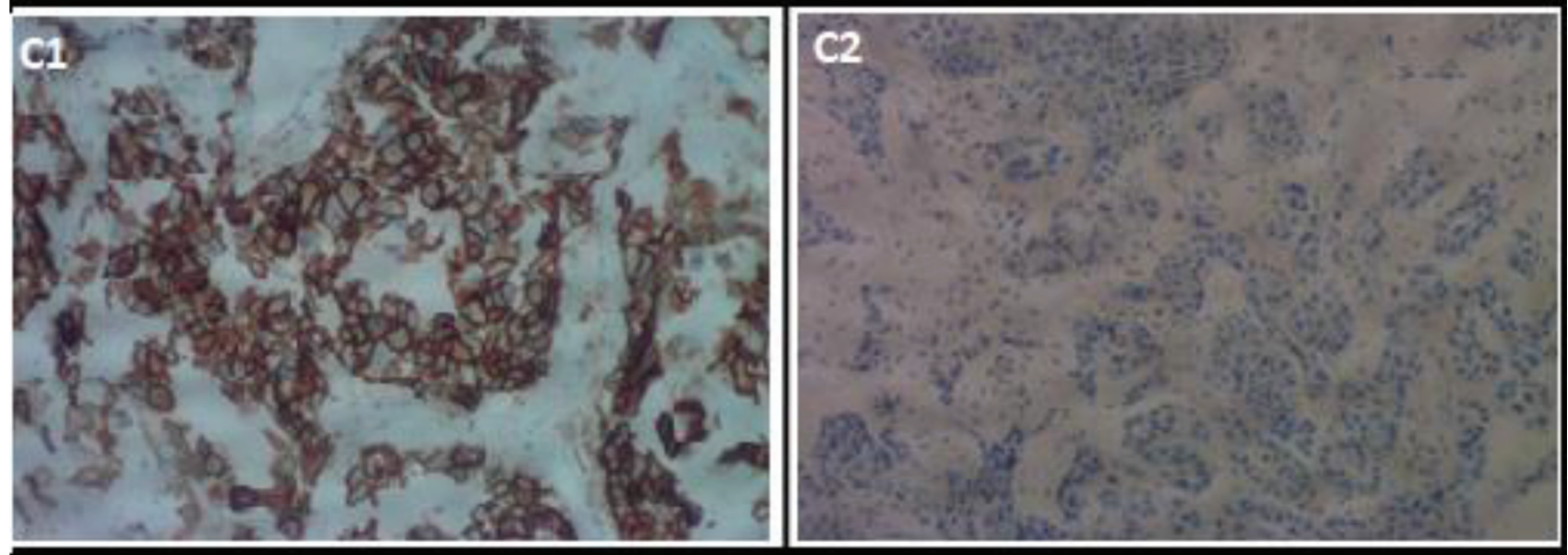

Fig. 4 (a1) Estrogen receptor (ER)-positive of invasive ductal carcinoma grade III 100×. (a2) ER-negative of invasive ductal carcinoma grade III 100×. (b1) Progesterone receptor (PR)-positive of infiltrating lobular carcinoma 100×. (b2) PR-negative of invasive ductal carcinoma, grade II 100×. (c1) Her-2/neu-positive 3+ of invasive ductal carcinoma, grade III 100×. (c2) Her-2/neu-negative of invasive ductal carcinoma grade III $100 \times$.

high histologic grade and more often triple-negative hormonal status. Therefore, there is a tendency toward poor response to hormonal therapy and poor prognosis.

Immunohistochemical evaluation of ER, PR, and Her-2/ neu is mandatory in all breast cancer patients so that the patient's treatment can be individualized. Our patients have started benefitting from this study. There is an increased awareness among clinicians and patients, and the management of the latter has been positively impacted upon. We hope that our patients will present earlier in the future for diagnosis and treatment, and with a lower tumor grade. The one-stop breast cancer clinic is expected to continue to save time between diagnosis and treatment. Furthermore, breast cancer screening program should be strengthened such that nonpalpable breast cancers can be detected very early.

\section{Note}

The datasets used and/or analyzed during the current study are available from the corresponding author on reasonable request. This study was approved by Lagos State 
University Teaching Hospital research ethical committee. All patients in the study gave written informed consent.

\section{Authors' Contributions}

All authors substantially contributed to the present study. S.D.A. conceived the study, performed immunohistochemical and histological analysis, and drafted the manuscript. J.0. participated in the design of the study, and reviewed and revised the manuscript critically for important intellectual content. P.A.O., I.N.A., O.F.O., and O.M.A. participated in sampling and design of the study, and reviewed the manuscript. E.F.E. participated in immunochemical and histological analysis. All authors read and approved the final manuscript.

\section{Previous Presentation}

The content of this manuscript has been presented in part as abstract at the Conference of American Pathologist: Sanni DA, Omodele FO, Popoola AO, et al. Hormone Receptors and HER-2/neu Overexpression in Breast Carcinomas in Patients of West African Origin Seen at Lagos State University Teaching Hospital, Nigeria. Arch Pathol Laboratory Med 2019;143(9):e2-226.

\section{Conflict of Interest}

None declared.

\section{References}

1 McPherson K, Steel CM, Dixon JM. ABC of breast diseases. Breast cancer-epidemiology, risk factors, and genetics. BMJ 2000;321(7261):624-628

2 Emmanuel AS. Age distribution and histological types of breast cancer in two major hospitals in the Niger Delta. Cont J Biomed Sci. 2011;5:37-42

3 Li CI, Uribe DJ, Daling JR. Clinical characteristics of different histologic types of breast cancer. $\mathrm{Br} \mathrm{J}$ Cancer 2005;93(9):1046-1052

4 Bhikoo R, Srinivasa S, Yu TC, Moss D, Hill AG. Systematic review of breast cancer biology in developing countries (part 1): Africa, the middle East, eastern Europe, Mexico, the Caribbean and South america. Cancers (Basel) 2011;3(2):2358-2381

5 Rambau PF, Chalya PL, Manyama MM, Jackson KJ. Pathological features of Breast Cancer seen in Northwestern Tanzania: a nine years retrospective study. BMC Res Notes 2011;4:214

6 Elumelu TN, Adenipekun AA, Abdus-Salam AA, Bojuade AD. Pattern of breast cancer metastasis at the radiotherapy clinic, Ibadan-a ten year review. J Am Sci 2011;7:906-912

7 Pitt JJ, Riester M, Zheng Y, et al. Characterization of Nigerian breast cancer reveals prevalent homologous recombination deficiency and aggressive molecular features. Nat Commun 2018;9(1):4181

8 Ikpatt OF, Kuopio T, Collan Y. Proliferation in African breast cancer: biology and prognostication in Nigerian breast cancer material. Mod Pathol 2002;15(8):783-789

9 Ezeome E, Emegoakor C, Chianakwana G, Anyanwu S. The pattern of male breast cancer in eastern Nigeria: a 12 year review. Niger Med J 2010;51:26-29

10 Giordano SH, Buzdar AU, Hortobagyi GN. Breast cancer in men. Ann Intern Med 2002;137(8):678-687

11 Tan EY, Wong HB, Ang BK, Chan MY. Locally advanced and metastatic breast cancer in a tertiary hospital. Ann Acad Med Singapore 2005;34(10):595-601

12 Omar S, Khaled H, Gaafar R, Zekry AR, Eissa S, el-Khatib O. Breast cancer in Egypt: a review of disease presentation and detection strategies. East Mediterr Health J 2003;9(3):448-463
13 Ikpatt OF, Kronqvist P, Kuopio T, Ndoma-Egba R, Collan Y. Histopathology of breast cancer in different populations: comparative analysis for Finland and Africa. Electronic J Pathol Histol 2002;8(4):1-8

14 Ntekim A, Nufu FT, Campbell OB. Breast cancer in young women in Ibadan, Nigeria. Afr Health Sci 2009;9(4):242-246

15 Conzen SD. Minireview: nuclear receptors and breast cancer. Mol Endocrinol 2008;22(10):2215-2228

16 Gowon AM. Current issues in ER and HER-2 testing by IHC in breast cancer. Mod Pathol 2008;21:8-15

17 Prichard JW. Overview of automated immunohistochemistry. Arch Pathol Lab Med 2014;138(12):1578-1582

18 Allred DC. Issues and updates: evaluating estrogen receptor- $\alpha$, progesterone receptor, and HER2 in breast cancer. Mod Pathol 2010;23(Suppl 2):S52-S59

19 Wolff AC, Hammond ME, Hicks DG, et al. American Society of Clinical Oncology; College of American Pathologists. Recommendations for human epidermal growth factor receptor 2 testing in breast cancer: American Society of Clinical Oncology/College of American Pathologists clinical practice guideline update. Arch Pathol Lab Med 2014;138(2):241-256

20 Akarolo-Anthony SN, Ogundiran TO, Adebamowo CA. Emerging breast cancer epidemic: evidence from Africa. Breast Cancer Res 2010;12(4(Suppl 4):S8

21 Achie LN, Olorunshole KV, Mabroule M. Age at natural menopause among Nigerian Women in Zaria, Nigeria. Asian J Med Sci 2011;3(8):151-153

22 Okonofua FE, Lawal A, Bamgbose JK. Features of menopause and menopausal age in Nigerian women. Int J Gynaecol Obstet 1990;31(4):341-345

23 Ozumba N, Obi SN, Obikili E, Waboso P. Age, symptoms and perception of menopause among Nigerian women. J Obstet Gynaecol India 2004;54(6):575-578

24 Bewtra C. Clinicopathologic features of female breast cancer in Kumasi, Ghana. Int J Cancer Res 2010;6(3):154-160

25 Adebamowo CA, Famooto A, Ogundiran TO, Aniagwu T, Nkwodimmah C, Akang EE. Immunohistochemical and molecular subtypes of breast cancer in Nigeria. Breast Cancer Res Treat 2008;110(1):183-188

26 Gukas ID, Jennings BA, Mandong BM, et al. Clinicopathological features and molecular markers of breast cancer in Jos, Nigeria. West Afr J Med 2005;24(3):209-213

27 Gukas ID, Girling AC, Mandong BM, Prime W, Jennings BA, Leinster SJ. A comparison of clinicopathological features and molecular markers in british and nigerian women with breast cancer. Clin Med Oncol 2008;2:347-351

28 Ahmed HG, Safi SH, Shumo AI, Abdulrazig M. Expression of estrogen and progesterone receptors among Sudanese women with breast cancer: immunohistochemical study. Sudan J Med Sci 2007;2(1):5-7

29 Suvarchala SB, Nageswararao R. Carcinoma breast-histopathological and hormone receptors correlation. Biosci Tech 2011;2(4):340-348

30 Fatima S, Faridi N, Gill S. Breast cancer: steroid receptors and other prognostic indicators. J Coll Physicians Surg Pak 2005; 15(4):230-233

31 Azizun-Nisa, Bhurgri Y, Raza F, Kayani N. Comparison of ER, PR and HER-2/neu (C-erb B 2) reactivity pattern with histologic grade, tumor size and lymph node status in breast cancer. Asian Pac J Cancer Prev 2008;9(4):553-556

32 Uslukaya Ö, Gümüş M, Gümüş H, Bozdağ Z, Türkoğlu A. The management and outcomes of male breast cancer. J Breast Health 2016;12(4):165-170

33 Wang-Rodriguez J, Cross K, Gallagher S, et al. Male breast carcinoma: correlation of ER, PR, Ki-67, Her2-Neu, and p53 with treatment and survival, a study of 65 cases. Mod Pathol 2002;15(8):853-861 